\title{
The Impact of Leadership Styles on Four Variables of Executives
}

\section{Workforce}

\author{
Dr. Galanou Ekaterini \\ Scientific Partner in the Business Administration Sector \\ Technological Educational Institute of Patras \\ Eitou 4, 26332 Patra, Greece
}

Tel: 69-420-527-723 E-mail: ketygalapatra@yahoo.gr

\begin{abstract}
Leadership is widely considered to be an important aspect of organizing and there are several reasons to suggest that managerial styles are of particular relevance in this context. However, there is a dearth of both theoretical and empirical work on leadership styles and their subsequent effects on middle managers' organizational commitment, their job satisfaction, their communication and their managerial effectiveness. The aim of this paper is to report the findings of an empirical study exploring the relationship between four prominent models of leadership and the fundamental organizational features such as commitment, satisfaction, communication and effectiveness, regarding a variety of measures of variables such as the organizational structure (i.e. the type of branch) and the managers' individual traits (i.e. the age, the education level).

The results reveal that, the spectrum of four leadership styles containing basic characteristics, such as the type of branches, the age and educational level are inter-related with communication, commitment, satisfaction, and effectiveness.
\end{abstract}

Keywords: Middle managers, Leadership style, Job commitment, Job satisfaction, Team communication, Managerial effectiveness, Quantitative research

JEL Classification: M12 - Personnel Management

\section{Introduction}

This study has attempted to collect and analyse data on a number of personal as well as organizational variables that are considered potentially useful in explaining the leadership styles of managers and the fundamental features such as their commitment, their satisfaction, their communication and their effectiveness. Such data include the gender, age, length of service in present organization, education level, hierarchy, size and type of organisation. The objective of the study is to examine the impact some of these variables have on the leadership style practices of managers and characteristics as commitment, satisfaction, communication and effectiveness.

While a significant amount of the research effort of the study of the leadership styles of managers has focused on only one personal dimension such as the impact of gender or age or education level differences (Collard, 2001;Eagly \& Johannesen-Schmidt, 2001; Kabacoff \& Stoffey, 2001;Schubert, 1988) or on one organizational aspect such as hierarchy and its impact on leadership ( Jacues, 1990; Mc Daniel \& Wolf , 1992; Stordeur, Vandenberghe \& D' hoore, 2000), it is believed that a better approach would be to examine both the personal and the organisational dimensions to effective leadership practices and the competences/situations of commitment, satisfaction, communication, effectiveness. For example, Gill (2003) is of the opinion that leadership behaviour theory and research appear to be disconnected and directionless because little consideration is given to both personal as well as organizational variables that influence the nature and impact of leadership.

In the modern management of human resources it is useful to investigate whether, there is less use of directive form of leadership in preference to transactional, transformational and empowering leadership practices. If so, such practices will be in line with the expected liberalisation in today' $\mathrm{s}$ world as different from yesterday' $\mathrm{s}$ more authoritarian styles of organisational management. Similarly, as Kabacoff (2002) remarked, it would be useful to know what personal characteristics, such as age, have on leadership practices which is supposedly based on some suggested principles. For example, how do older and younger top or medium level organizational leaders differ in their leadership activities? Knowledge of the answers to these and similar questions can be used to improve the management of human resources. 
The present work, therefore, attempts a more comprehensive research of the leadership styles of managers examined from both personal as well organisational dimensions to give a more complete picture describing both the individual as well the joint impact of these variables on managerial practice.

Collecting data from over 190 managers from an organization in Greece and consistent with our objectives, the balance of this article will briefly review the literature on the extent to which personal and organisational variables could, individually and in various ways, affect the practice of leadership. It will discuss research studies exploring similarities and differences in the leadership styles of managers based on personal as well as organisational considerations. After outlining details of the method adopted for the study, its results will be presented and discussed and their implications will be explored. A summary and the conclusions of the study will finally be highlighted.

\section{Theoretical underpinnings of the study}

The nature of an organization's human capital and the way it is managed can have an impact on employee and firm performance (Wright, McMaham, \& MacWilliams, 1994; Wright \& Snell, 1998). Within this strategic human resource management literature, researchers suggest that employees differ in the importance of their contribution to the organization's success (Delery, 1998). As a result, organizations may adopt different human resource management practices for different employment groups based on variations in their levels of knowledge, skills, abilities, and expertise, as well as, expectations concerning psychological contracts, organizational commitment, and the like (Lepak \& Snell,1999a; Tsui,Peace, Porter \&Hite,1995; Tsui,Pearce,Porter, \& Tripoli,1997).

Just as researchers recognize that different workers exhibit a variety of perceived obligations and expectations in their exchanges with their firm (Robinson, 1996), a similar distinction exists within the leadership literature. That is, the leadership literature has a rich tradition of conceptualizing leadership typologies. In a typical typology, leader behaviors are theoretically clustered into prominent types of styles of leadership.

As known, the path-goal theory identified four distinct styles of leader behaviors - supportive leadership, directive leadership, achievement- oriented leadership, and participative leadership (House, 1986). More recently, the dominant typology is that articulated by Bass $(1981,1997)$ and his associates (e.g. Bass \& Avolio, 1993; Bass, Avolio \& Goodheim, 1987) who suggest a transactional- transformational paradigm.

In this study, the researcher drawn on this tradition used the rich historical leadership literature to conceptualize four major types or styles of leadership to use in the contingency theory. Fundamentally, the typology is consistent with the viewpoints of Bass, but it is extended to include other views or types.

Researcher's historical analysis is adapted from Pearce et al. (2000). For each style, we draw from several theoretical roots of specific leader's behaviors as well as broader theoretical theories that can be related to leader behavior.

The roots are summarized in the table below:

MODELS OF LEADERSHIP TYPES

Leadership type

Theoretical bases

Directive leadership

Theory X leadership (Mc Gregor, 1960)

Initiating Structure from Ohio State studies (Fleishman, 1953)

Task-oriented behavior from Michigan studies (Katz, Maccoby, \& Morse, 1950)

Punishment research (Arvey \& Ivancevith, 1980)

Transactional leadership Expectancy theory (Vrom, 1964)

Path-goal theory (House, 1971)

Equity theory (Adams, 1963)

Exchange theory (Homans, 1961)

Reinforcement theory (Luthans \& Kretner, 1985;Sims, 1977)

Reward research (Podsakoff, Todor \& Skov, 1982)

Transformational leadership

Sociology of charisma (Weber,1946)

Charismatic leadership theory (House, 1977)

Transformational leadership (Bass, 1985;Burns, 1978)

Empowering leadership Behavioral self-management (Thorenson \& Mahoney, 1974) 
Social cognitive theory (Bandura, 1986),

Cognitive behavior modification (Meichenbaum, 1977)

Participative management and participative goal-setting research (Likert, 1961, 1967; Locke \& Latham, 1990)

From Pearce et al. (2000)

The influence of leadership style on job performance, organisational commitment and satisfaction has been well established (Breckenridge, 2000; Vries et al., 1998; Cairns, 1996). While leadership style has an impact on organisations, department, and teams, as well as work climate and atmosphere, leaders who want the best results should not rely on a single leadership style (Goleman, 2000).

Empirical evidence has been produced whose demographic variables such as years in organisation, age, level of education and the duration of leadership (Chen \& Francesco, 2000; Mathieu \& Zajac, 1990) can have significant impact on organisational commitment. Sommer et al. (1996) revealed that position, tenure and age were significantly related to employee commitment for korean subjects, which were consistent with the western results.

Mitchell (2000) suggests that several factors account for generational differences in the attitudes and behaviour of workers. The level of education and age were identified as important determinants. He suggests that the level of education influences people's values, wants and needs and makes them think and behave differently. Age, on the other hand, tend to give greater or lesser degree of expression of individualism among the workers with the younger generations feeling more comfortable exhibiting individualistic behaviours. Collecting their data from American and Canadian managers in a variety of organisations, Kabacoff \& Stoffey (2001) carried out a large sample survey on age differences in organisational leadership. Their basic findings are summarised into two lists (Kabacoff, 2002). On leadership styles and behaviour, compared with older workers, the researchers found that younger workers feel more comfortable in fast changing environments and more willing to take risks and consider new approaches. They also operate with more energy and intensity, and have a greater capacity to generate enthusiasm in others. In addition, they are more likely to seek out opportunities to take charge and push vigorously and competitively to achieve a high level of results. Compared with older workers, younger workers also tend to work to develop and promote themselves. Similarly, on leadership styles and behaviour, compared with younger workers, the researchers found that older workers study problems in the light of past practices in order to ensure predictability, and minimise risk. They tend to maintain a calmer and more understable (though not detached) demeanour. Older workers tend to maintain an in-depth knowledge of their field and use this knowledge to approach problems. They cooperate and delegate more, and show a greater degree of concern for other workers.

In a monograph, Edwards (2000) summarises the views of several authors on differences in leadership styles and behaviour across organisational variables (size, type, structure) on organisations. He reviews the recommendations of Khaleelee \& Woolf (1996), that leadership should be demonstrated in all types of an organisational structure, as they believe that effective leadership is a prerequisite for organisational success.

Organisational commitment, job satisfaction and communication are variables that can be the major determinants of organisational performance (Riketta, 2002; Kramer, 1999; Angle, 1981) and effectiveness (Lashchinger, 2001).Some studies have reported strong correlations of organisational commitment, communication and job satisfaction with turnover (Benkhoff, 1997; Baugh \& Roberts, 1994). When employees are dissatisfied at work, they are less committed and will look for other opportunities to quit. If opportunities are unavailable, they may emotionally or mentally "withdraw" for the organisation. Thus, organisational commitment, communication and job satisfaction are important attitudes in assessing employee's intention to quit and the overall contribution of the employee to the organisation. Numerous antecedents of job satisfaction, organisational commitment and communication have been suggested in the earlier studies (Chen \& Francesco, 2000; Mathieu \& Zajac, 1990). For example, leadership (Williams \& Hazer, 1986) was shown to have significant impact on all three of them, organisational commitment, communication, job satisfaction (Lok \& Crawford, 1999; 2001). Also, earlier studies have shown that organisational variable of leadership can affect managerial styles (Westwood \& Posner, 1997) and employee behaviour (Chen \& Francesco, 2000; Miroshnik, 2002).

In the area of managerial effectiveness, managers must have a mutual understanding of the skills and responsibilities necessary for other managers across similar and different organizational levels and functions (Kraut et al., 1989). If these skills and responsibilities are not clearly understood, managers will not be able to coordinate work effectively, communicate expectations, deliver feedback, or be prepared for job transitions or 
other training and career development activities (Kraut et al., 1989). Managers must fully understand their roles and responsibilities and become adept at a variety of skills to perform their job effectively (Ahearn et al., 2004; Halbesleben et al, 2003; Stockdale and Crosby, 2004; Wallace, 2004; Zaccaro et al., 2004).

Management development specialists are interested in the synergistic elements (organisational commitment, managerial effectiveness, team communication, job satisfaction) impact on an organisation type structure, managers personal features and the managers' leadership styles they use. Therefore, further research and investigation is warranted in analysing this synergistic impact.

\section{Research method}

To indentify the impact of personal as well as the organizational influences and the explanations for the managers' leadership styles in Emporiki Bank along with their communication, commitment, satisfaction, and effectiveness, the following research method was employed in the study. A building block of the organizational structure within Emporiki (and consequently, within the majority of banking or financial institutions) is the "Branch". The Emporiki bank' s branches are mainly operating in 3 modes according to:(i) the capacity of their employees,(ii) their employees' job responsibilities, and (iii)the products and services they offer to the businesses and to the individuals. The subdivision of the branches is as follows: 1. Full Service Branches, 2. Medium-Sized Businesses and Individual's Branches, 3.Individual Customers Service Branches.

\subsection{Sample and procedures}

A questionnaire survey was conducted where the population for the study was 300 managers. They were sent by Lotus Notes, which is the internal electronic communicational system of the Emporiki Bank.

The questionnaires were sent randomly to all the branches of Greece and without selection of their category whether it was $\alpha$ ) Full Service Branches, $\beta$ ) Medium- Sized Businesses and Individual's Branches, and c) Individual Customers Service Branches. The questionnaires covered managers from all the regions of the country in which there were branches of Emporiki Bank.

The researcher opened up the e-book with the addresses of the branches of the Bank and sent the questionnaires in random order. They were accompanied by a descriptive letter which reported the subject of the research, the great importance that their participation had for the completion of the research, the secrecy of their answers and their capability for access to the results of the research when the research came to its consummation. Also, the professional title of the researcher was reported in the letter.

A total of one hundred ninety completed and usable questionnaires were returned, for a response rate of 63,3 per cent with a reminder being done by the researcher' s phone-call. The medium response rate was explicable, and the explanation was suggested as the middle managers' lack of free time and the pressure and limitations they faced in their everyday routine. Also, in some cases the reasons included individual practices of non-response to unsolicited surveys (Waldman, Ramirez, House \& Puranam, 2001). Overall, the number of responses to our survey was considered reasonable and adequate for statistical analyses.

The questionnaire requested respondents to indicate the ways through which they dealt with their day-to-day activities. The different questions they answered corresponded to 1) four leadership styles (transactional, transformational, empowering, directive); 2) their competences which influence the managers' performance (communication, personal effectiveness) and 3) their commitment and their job satisfaction. Similarly, respondents were also asked to indicate where they belong in the organizational characteristics, namely: Full Service Branches, Medium- Sized Businesses and Individuals Branches and Individual Customers Service Branches. Similarly, respondents were also asked to indicate their age among the 4 age groups specified in the survey, namely:1) up to 30, 2) $31-45,3) 46-60$ and 4)60-65. Also, respondents were also asked to indicate what educational level they occupied, among the 4 Levels of Education groups specified in the survey, namely:1) Without Certificate, 2)Bachelor, 3)University Degree, 4) Master.

The meaning attached to each question of the leadership styles dimensions and the features such as commitment, job satisfaction, communication and effectiveness was explained in the survey and the rating adopted a Likert-type scale from 1 (Not at all), 2 (Once in a while), 3 (Sometimes), 4 (Fairly often), and 5 (Frequently, If not always). The questionnaire, thus, incorporated a self-report version with authentic questionnaires, borrowing of course, some parts of standardise questionnaires which should be adapted to the Greek reality.

For the needs of this current study, it is adopted the principle that, the degree of appearance of the elements of commitment and satisfaction in managers' behaviour and of the degree of existing competences of communication and effectiveness, demonstrates that they possess them. 
It should be stated that some authors, e.g. Hogan \& Hogan (2001) and Podsakoff \& Organ (1986), are critical of self- report data used in leadership research, as they contend that leadership is a social influence process and thus, should be determined by manager' s staff/direct reports. While Gill (2003) accepts the fact that self-reports are open to criticism he nevertheless argues that they can be valid and useful in certain circumstances, when he felt that the need for socially desirable responses is absent or minimal. Indeed, Saville, Sik, Nyfield, Hackston and MacIver (1996) have demonstrated how "self-report personality scales show predictable, significant and substantial correlations with criteria of management job success. The authors also suggest that: 'It is important not to exaggerate the problem of social desirability in responding.' And according to Hough, Eaton, Dunnette, Kemp and McCloy (1990), response distortion due to social desirability does not appear to affect validity coefficients significantly.

As indicated above, the questionnaire also contained information on respondents' age, level of education, type of branch of the organisation they worked for. The aim of collecting the latter set of data was to explore their utility in describing the leadership styles of managers and their competences (organizational commitment, job satisfaction, team communication and effectiveness). Although typically used as control variables in many types of studies, the items age, education, e.t.c. are used as independent variables in this research while the various forms of leadership styles and competences are the test or dependent variables.

\section{Results}

The mean, standard deviations and inter-correlations among each of the leadership styles are presented in Table 1a, 1b, as well as the values of the Cronbach's alpha for the distribution. These statistics are generally satisfactory and our results showed significant correlations for each group of questions.

To examine the issue of relationship among the four styles of management and the fundamental features such as commitment, satisfaction, communication and effectiveness by the level of characteristics (kind of bank, age, education), an analysis was carried out with cross-tabulation.

The appropriate plots and the observation of how much different results are given by the levels of the three independent variables (kinds of bank, age, education) concerning the four leadership styles and four characteristics as commitment, satisfaction, communication and effectiveness, which are the main variables (depended variables) of the current research, lighted the structure and the pattern of the variables.

A proper pair of hypotheses that was used was that there is independence between the pair of the variables that is being examined each time and that there is not independence in the alternative hypothesis. The pair of the hypothesis is: a) $\mathrm{H}_{0}$ : the correlation between $\mathrm{i}$, $\mathrm{j}$ variables is not significant. And b) $\mathrm{H}_{1}$ : the correlation between $\mathrm{i}$, $\mathrm{j}$ variables is significant.

After the estimation of the Pearson's statistic chi-square, the test was based on the p- value (observed level of statistical significance). Since the significance level, a, is 5\%, values of the observed level of statistical significance less than $5 \%$ cast doubt on the acceptance of the Ho hypothesis.

Tables 2.a to 2.c summarise the results of the Chi-square Statistic of dependence as well as the corresponding p-values of the Test of Dependence conditional on the three kinds of banks, the two groups of ages, the three levels of education respectively.

\section{Discussion}

This section of the article discusses the empirical analyses and results presented under the results section. The statistically significant findings in relation to explanatory leadership styles were the described "Table dependence- independence" results (table 3), summarizing the impact of independent variables of age, education and type of branches of four leadership styles in the organization and the fundamental features such as commitment, satisfaction, communication and effectiveness. Additionally, the findings of this study gave considerable interest in the assessment of managerial effectiveness and examined the influence of preferred managerial styles on effectiveness (Tett et al., 2000). This discussion is subdivided into 4 parts, namely: the impact of directive leadership style, empowering leadership style, transformational leadership style and transactional leadership style.

\subsection{The impact of directive leadership style}

A part of Table 2a.-2c pertains to directive leadership style and it is the extent to which a manager attains desired objectives by telling subordinates or others what to do and how to do it. The results of the analysis suggest that managers' education level is a significant predictor of the use of directive leadership - the higher the managers' education level is, the less directive leadership that takes place. This result is as expected. Higher 
education level of leaders tend to give the most time broad outlines, opinions and suggestions rather than directives to their staff. On the other hand, managers with lower education level often need to give specific directives to facilitate operatives in doing exactly what is expected of their peers and when.

It is interesting to observe, under directive leadership, that the interaction of age and type of organisational structure in combination with the satisfaction, commitment, communication and effectiveness, in the present organisation is positively and statistically significant (table $2 \mathrm{a}-2 \mathrm{c}$ ). These results suggest that given that higher education level is consistent with the use of less directive leadership, age may positively has an impact on the use of directive leadership. Older leaders can draw on their years of experience to specifically make decisions with greater degree of confidence which younger managers do not seem to possess.

\subsection{The impact of empowering and transformational leadership styles}

Empowering leadership style is the extent to which the managers attain desired objectives by leaning subordinates or others to make their own decisions, share a consensual decision-making process with their subordinates or others to achieve their objectives. In this scenario, the resulting decision is a joint one between the managers and subordinates. Transformational leadership style, on the other hand, shares a consensual decision-making process with their subordinates or others to achieve their objectives. In this scenario, the resulting decision is a joint one between the managers and subordinates.

The results of empowering and transformational leadership styles, in tables 2a-2c, are similar one to another in the sense that kind of bank, age and Level of education are individually statistically significant (positively or negatively) in most cases. These results suggest that the higher the level of education, the less transformational and empowering leadership occur. Therefore, the managers that hold a University degree, use both of the two leadership styles and data shows that, they have a positive relation with the satisfaction, commitment, communication, and effectiveness.

However, while two of the three education levels are negatively associated with each of transformational and empowering leadership styles, a kind of organisational structure is positively associated with each of the two variables. Also table $2 b$ indicates rather a strong significance of the couple variables empowering stylecommitment, empowering style- communication, empowering style- satisfaction, empowering styleeffectiveness, transformational style-commitment, transformational style -communication, transformational style-satisfaction and transformational style-effectiveness when the managers are 36-45 years old. At the age 46-60 there is not a good relationship for the above mentioned couple of variables.

In general, the results seem to suggest that the older an employee the less the level of empowering and participation that he tends to engage in within organization in the performance of his job is too. As a result of greater use of more and more technology today, older workers are rather not eager to follow the changes, they feel rather panicked and don't share their experience with others.

\subsection{The impact of transactional leadership style}

Transactional leadership style is the extent to which the managers discuss matters with their subordinates or others before they decide what to do to achieve unit objectives. Here, although the managers support, the resulting decision is theirs alone and they shoulder the responsibility for them. Tables $2 a-2 c$ pertains to this style too. The results suggest that age is not positively related to transactional leadership at the age 46-60. This suggests that older managers have a tendency to shoulder the responsibilities of their decisions less than younger managers. This can be a result of their bad relation with higher level of management or because they see their pension come soon. The results show that , the transactional leadership used to the bigger organization structure (type of branch), while as far as the involvement of this style in combination with the satisfaction, commitment, communication, effectiveness are concerned, there is not a good relationship with any level of their education.

This study sets out to examine the leadership styles of managers from the perspectives of their ages, their level of education and the type of organizational structure, in the organization they work. Using survey data from 190 managers from Emporiki bank in Greece, it was found that managers can use the four leadership styles at all types of branches of the bank. However, it was also found that older managers and at higher education levels tend to use a composite leadership style (a situational leadership style) rather than to select an appropriate style of leadership in performing their organizational activities. The above logical aspects find theoretical basis on contingency approach to leadership (e.g. LMX theory: Graen, 1982; path- goal theory; House, 1999; situational leadership theory: Hersey \& Blanchard, 1988). According to George (2003), to be authentic in your management behaviour means that you have to develop your own style in accordance with your personality and character. Whetten et al. (2000) emphasized the importance of intrapersonal skills for effective management. This means, 
according to their perspective developing self-awareness on the basis of a thorough analysis of one's strengths and weaknesses. Understanding the interplay between people's preferences and their day-to-day workplace behaviour is crucial for designing and implementing effective individual development efforts (Berr et al., 2000; Riding and Rayner, 1998). People can be trained to adopt strategies to overcome the weaknesses of their styles in specific situations (Armstrong and Sadler-Smith, 2006; Hough and Ogilvie, 2005).In this regard, some relevant action points were identified to enhance managerial style awareness. Importantly, no style is inherently better than another. Schroder (1994), for instance, found that leadership styles are independent of management competence, but do influence the way in which management competence is expressed. Understanding the implications of leadership styles differences can be a basis for fostering better working relationships (Allinson et al., 2001). Overlooking the impact of leadership styles differences can lead to interpersonal disagreements and conflict situations, as people with different leadership styles may not understand or respect each other. Thus, to be successful, effective managers should be aware of their own way to lead and those of the people that surround them. George (2003) saw dealing with different types of people as an important developmental task for managers. Managers can increase their effectiveness by working collaboratively with people with various cognitive styles and paying attention to different points of views, attitudes, behaviours, perspectives, and actual cognitions (Riding and Rayner, 1998)

One limitation in this study is the nature of the sample. The subjects came from one type of bank sector. It is Emporiki Bank with a course of special characteristics in its history, its culture, its philosophy, managerial practices and its values. It would be interesting for future studies to investigate the above issues, by contrasting the diverse types of organizations working in a multinational corporation or in a family owned business. Recently, much attention has been devoted to the importance of the organizational context in organizational studies (Johns, 2006).

Another limitation is that the sample of the managers was examined in a spectrum of four leadership styles. If the spectrum of leadership styles was drawn from a wider range, it is possible that the results would be different. Furthermore, it can also be of interest to study managerial styles from the perspective of co-workers (subordinates, peers, supervisors), as they are in a unique position to provide valuable behavioural assessments for two reasons (Berr et al., 2000). On the other hand, colleagues are often influenced by the consequences of the focal person's actions. On the other hand, they can observe this behaviour over time and in a variety of situations.

\section{References}

Ahearn,K.K., Ferris, G.R., Hochwarter, W.A., Douglas, C., \& Ammeter, A.P. (2004). Leader political skill and team performance. Journal of Management, 30, 309-27

Allinson, C.W., Armstrong, S.J., and Hayes, J. (2001). The effects of cognitive style on leader-mamber exchange: a study of manager-subordinate dyads. Journal of Occupational and Organizational Psychology, 74 (2), 201-20

Angle,H. (1981). An Empirical Assessment of Organizational Commitment and Organisational Effectiveness. Administrative Science Quarterly, 26(1), 1-14

Armstrong, S.J., and Sadler-Smith, E. (2006). Cognitive style and its relevance for the management of careers, paper presented at the $66^{\text {th }}$ Academy of Management Conference, Atlanta, GA, 11-16 August

Bass B. M., \& Avolio B. J. (1993). Transformational leadership : a response to critiques, In J. G. Hunt, B. R. Baliga, H. P. Dachler \& C. A.Schriesheim (Eds). Emerging leadership vistas, p.29-40, Lexington, MA: D.C. Health

\section{Bass B.M. (1981). Handbook of Leadership: A survey of theory and research. New York: Free Press}

Bass B.M. (1997). Does the transactional- transformational leadership paradigm transcend organizational and national boundaries? American Psychology, 52(3), 130-9

Bass B.M., Avolio B.J., \& Goodheim L. (1987). Biography and the assessment of transformational leadership at the world-class level. Journal of Management, 13, 7-19

Baugh, S.G., and Roberts, R.M. (1994). Proffessional and Organisational Commitment Among Engineer: Conflicting or Complementary?, IEEE Transaction on Engineering Management, 41(2), 108-14

Beer, S.A., Church, A.H., and Waclawski, J. (2000). The right personality is everything: linking personality preferences to managerial behaviors. Human Resource Development Quarterly, 11(2), 133-57 
Benkhoff, B. (1997). Disentangling Organisational Commitment: the changes of the OCQ for Research and Policy. Personnel Review, 26(1), 114-20

Breckenridge, M.B. (2000). An exploration of the Factors that Influence Leadership Effectiveness in a Corporate Environment. Indiana University of Pennsylvania, Indiana, PA

Cairns, T.D. (1996). Hersey and Blanchard's situational leadership theory: a study of the leadership styles of senior executives in service and manufacturing businesses of a large Fortune 100 company. unpublished doctoral dissertation, Nova Southeastern University, Fort Lauderdale, FL

Chen, Z.X., and Francesco, A.M. (2000). Employee Demography, Organisational Commitment, and turn over intentions in China: do cultural differences matter?, Human Relations, 3(6), 869-87

Collard, J.L. (2001). Leadership and Gender: An Australian Perspective, Educational Management and Administration, 29, 343-355

Delery J.E. (1998). Issues of fit in strategic human resource management: implications for research, Human Resource Management Review, 8, 289-310

Eagly, A.H., and Johanneses-Schmidt, M.C. (2001). The Leadership Styles of Women and Men. Journal of Social Issues, 57, 781-797

George, B. (2003). Authentic Leadership. Jossey-Bass, San Francisco, CA

Gill, R. (2003). Towards an Integrative Model of Leadership, paper delivered at a Research Seminar. Queen's University of Belfast, School of Management and Economics, December

Goleman, D. (2000). Leadership that gets results. Harvard Business Review, March-April, 78-90.

Graen G., Liden R., \& Hoel W. (1982). The role of leadership in the employee withdrawal process. Journal of Applied Psychology, 65,868-872.

Halbesleben, J.R.B., Novicevic, M.M., Harvey, m.g., \& Burkley, M.R. (2003). Awareness of temporal complexity in leadership of creativity and innovation: a competency-based model. The Leadership Quarterly, $14,433-54$

Hersey p., \& Blanchard K.H. (1988). Management of Organizational Behavior: Utilizing Human Resources. Prentice Hall International, Englewood Cliffs, NJ, 1988

Hogan, R., and Hogan, J. (2001). Assessing Leadership: A View from The Dark Side. International Journal of Selection and Assessment, 9, 40-51

Hough, J.R., and Ogilvie, D.T. (2005). An empirical test of cognitive style and strategic decision outcomes. Journal of Management Studies, 42(2), 417-48

Hough, L., Eaton, N.K., Dunnette, M.D., Kemp, J.D., and McCloy, R.A. (1990). Criterion-related Validities of Personality Constructs and the Effect of Response Distortion on those Validities. Journal of Applied Psychology, 75, 581-595

House R.J. (1999). Weber and neo-charismatic leadership paradigm: a response to Beyer. Leadership Quarterly, $10,563-574$

House R.J., Woycke J., \& Fodor E.M. (1986). Charismatic Leadership in US Presidential Office, paper presented at the annual Academy of Management Meetings, San Diego, California

Jacques, E. (1990). In Praise of Hierarchy. Harvard Business Review, 68, 127-133

Johns, G. (2006). The essential impact of context on organizational behavior. Academy of Management Review, 31 (2), 386-408

Kabacoff, R.I. (2002). Leadership: What Has Age Got to do With It?, Research Release, New York: Management Research Group.

Kabacoff, R.I., and Stoffey, R.W. (2001). Age Differences in Organisational Leadership paper presented at $16^{\text {th }}$ Annual Conference of the Society for Industrial and Organisational Psychology, San Diego: California

Krammer, M.W. (1999). Motivation to Reduce Uncertainty: a Reconceptualization of Uncertainty Reduction Theory. Management Communication Quarterly, 13(2), 305-16

Kraut,A.I., Pedigo, P.R., McKenna, D.D., \& Dunnette, M.D. (1989). The Role of the Manager: what's really important in different management jobs. Academy of Management Executive, 3, 286-93 
Laschinger, H. (2001). The Impact oof Workplace commitment, Organisational Trust on Staff nurces' work Satisfaction and Organisational Commitment. Health Care Management Review, 26(3), 7-24

Lepak D. P., \& Snell S. A. (1999a). The human resource architecture: Toward a theory of human capital allocation and development. Academy of Management Review, 24, 31-48

Lok, P., and Crawford, J. (1999). The Relationship between Commitment and Organizational Culture, Subcultures, Leadership Styles, Job Satisfaction in Organizational Change and Development. Leadership and Organizational Development Journal, 20 (7), 365-73

Mathieu, J., and Zajac, D. (1990). A review of Meta-analysis of the Antecedents, correlates and consequences of Organizational Commitment, Psychological Bulletin, 108(2), 171-94

McDaniel, C., and Wolf, G.A. (1992). Transformational Leadership in Nursing Service: A test of Theory. Journal of Nursing Administration, 22, 60-65

Miroshnik, V. (2002). Culture and International management: a Review. Journal of Management Development, 21(7), 521-44

Mitchell, S. (2000). American Generations-Who They Are. How They Live. What they Think (3 ${ }^{\text {rd }}$ ed.) Ithaca, N.Y.: New Strategic Publications, Inc

Pearce C.L., Sims Jr. H.P., Cox j., Ball G., Schnell E., Smith K.A. \& Trevino L. (2000). Transactors, transformers, and beyond: a multi-method development of a theoretical typology of leadership. Working paper, University of Maryland

Podsakoff, P.M., and Organ, D.W. (1986). Self-reports in Organisational Research: Problems and Prospects. Journal of Management, 12, 531-544

Riding, R., and Rayner, S. (1998). Cognitive Styles and Learning Strategies: Understanding Style Differences in Learning and Behaviour, Fulton, London

Riketta, M. (2002). Attitudinal Organizational Commitment and Job Performance: a meta-analysis. Journal of Organizational Behavior, 23, 257-66

Robinson S. L. (1996). Trust and breach of the psychological contract. Administrative Science Quarterly, 41,574-599

Saville, P., Sik, G., Nyfield, G., Hackston J., and MacIver, R. (1996). A Demonstration of the Validity of the Occupational Personality Questionnaire in the Measurement of Job Competencies across Time and in Separate Organisations. Applied Psychology: An International Review, 45, 243-262

Schroder, H.M. (1994). Managerial competence and style, in Kirton, M.J. (Ed.). Adaptors and Innovators:Styles of Creativity and Problem Solving, Routledge, New York, NY, 91-113

Schubert, J.N. (1988). Age and Active-passive Leadership Style. American Political Science Review, 82, 763-773

Sommer,S., Bae, S., and Luthans, F. (1996). Organisational Commitment across cultures: The impact of antecedences on Korean employees. Human Relations, 9(7), 977-93

Stockdale, M.S., \& Crosby, F.J. (2004). The psychology and Management of Workplace Diversity. Blackwell Publishers, Malden, MA,

Stordeur, S., Vandenberghe, C., and D'hoore, W. (2000). Leadership Styles across Hierarchical Levels in Nursing Departments. Nursing Research, 49, 37-43

Tett, R.P., Guterman, H.A., Bleier, A. and Murphy, P.J. (2000). Development and content validation of a "hyperdimensional" taxonomy of managerial competence. Human Performance, 13(3),205-51

Tsui A.S., Pearce J.L., Porter L.W., \& Hite J.P. (1995). Choice of employee-organization relationship: influence of external and internal organizational factors. Research in Personnel and Human Resources Management, 13, 117-151

Tsui A.S., Pearce J.L., Porter L.W., \& Tripoli A.M. (1997). Alternative approaches to the employee-organization relationship: does investment in employees pay off? Academy of Management Journal, 40, 1089-1121

Vries, R.E., Roe, R.A., and Taillieu, T.C.B. (1998). Need of supervision: its impact on leadership effectiveness. The Journal of Applied Behavioral Science, December, 486-501 
Waldman, D.A., Ramirez, G.G., House, r.j., \& Puranam, P. (2001). Does Leadership Matter? CEO Leadership Attributes and Profitability under Conditions of Perceived Environmental Uncertainty. Academy of Management Journal, 44, 134-143

Wallace, P. (2004). The Internet in the workplace: How new technology is Transforming Work. Cambridge University Press, New York, NY.

Westwood, R., and Posner, B. (1997). Managerial Values across Cultures: Australia, Hong Kong and the United States. Asia Pacific Journal of Management, 14, 31-66

Whetten, D., Cameron, K., and Woods, M. (2000). Developing Management Skills for Europe, $2^{\text {nd }}$ ed. Pearson Education, Harlow

Williams, L., and Hazer, J. (1986). Antecedences and Consequences of Satisfaction and Commitment in turnover modes: a re-analysis using Latent Variables Structural Equation Methods. Journal of Applied Psychology, 71(2), 219-31

Wright P.M., \& Snell S.A. (1998). Toward a unifying framework for exploring fit and flexibility in strategic human resource management. Academy of Management Review, 23, 756-772

Wright P.M., McMahan G.C., \& MacWilliams A. (1994). Human Resources and sustained competitive advantage: a resource-based perspective. International Journal of Human Resource Management, 5, .301-326

Table 1a. Means, standard deviations and intercorrelations among the variables.

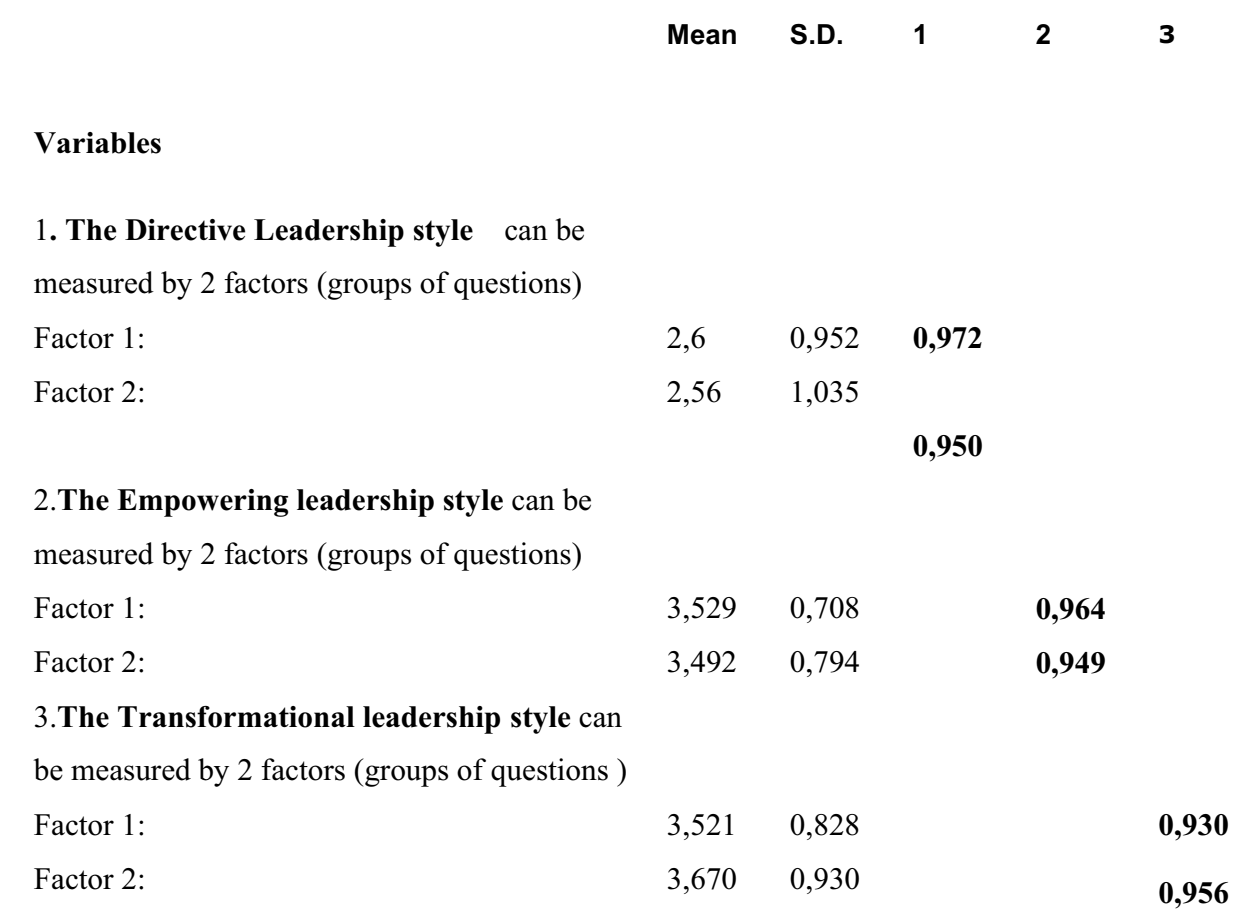

4.The Transactional leadership style can be measured by 1 factor (group of questions )

$\begin{array}{llll}\text { Factor 1: } & 4,089 & 0,923 & \mathbf{0 , 8 7 4}\end{array}$

Note: Extraction method: One-way ANOVA analysis. a. 1= The Directive Leadership style. b. 2= The Empowering leadership style c. 3 = The Transformational leadership style d. $4=$ The Transactional leadership style. e. S.D. $=$ Standard deviation. f. Bold values across the diagonal are reliability alphas 
Table 1b.

\section{Variables}

Directive

Leadership

style

Empowering

leadership

style

Transformatio

nal leadership

style

Factor 1:

Factor 2:

Factor 1:

Factor 2:

\section{Factor 1: $\quad \mathrm{a}=0,972 \quad \mathrm{p}=0,2335$}

Factor 2 : $\quad \mathrm{a}=0,950 \quad \mathrm{p}=$

0,3973

$$
\begin{array}{ll}
a=0,964 & p=0,1428 \\
a=0,949 & p=0,2147
\end{array}
$$

$$
\begin{aligned}
& a=0,930 \\
& p=0,0404 \\
& a=0,956 \\
& p=0,1541
\end{aligned}
$$

Transactional Factor 1:

$\mathrm{a}=0,874$

leadership

$\mathrm{p}=0,5359$

\begin{tabular}{|c|c|c|c|c|c|c|c|c|c|c|c|c|}
\hline \multirow[t]{2}{*}{ Table 2a } & \multicolumn{4}{|c|}{ Bank $=1$ * } & \multicolumn{4}{|c|}{ Bank $=2 \ldots$} & \multicolumn{4}{|c|}{ Bank $=3^{k * *}$} \\
\hline & Com/ment & Satis/on & Com/on & Ef/ness & Com/ment & Satis/on & Com/on & Effness & Com/ment & Satis/on & Com/on & Effiness \\
\hline \multirow[t]{2}{*}{ Direetive } & 47,518 & 41,265 & 32,713 & 29,228 & 21,277 & 34,815 & 16,853 & 23,754 & 26,303 & 53,352 & 38,268 & 18,357 \\
\hline & 0,000 & 0,000 & 0,001 & 0,004 & 0,046 & 0,000 & 0,032 & 0,022 & 0,001 & 0,000 & 0,000 & 0,019 \\
\hline \multirow[t]{2}{*}{ Empowering } & 38,157 & 31,717 & 34,211 & 29,056 & 20,467 & 40,357 & 22,619 & 21,797 & 35.530 & 57,600 & 45,740 & 18,938 \\
\hline & 0,000 & 0,002 & 0,001 & 0,004 & 0,059 & 0,000 & 0,004 & 0,040 & 0,000 & 0,000 & 0,000 & 0,015 \\
\hline \multirow[t]{2}{*}{ Ttransformatonal } & 26,468 & 39,729 & 32,983 & 19,418 & 26,893 & 30,344 & 18,715 & 19,752 & 30,596 & 35,442 & 25,598 & 16,487 \\
\hline & 0,002 & 0,000 & 0,000 & 0,022 & 0,001 & 0,000 & 0,005 & 0,020 & 0,000 & 0,000 & 0,000 & 0,011 \\
\hline \multirow[t]{2}{*}{ Transactional } & 11,202 & 5,164 & 2,253 & 11,377 & 14,050 & 26,912 & 8,425 & 4,421 & 16,522 & 8,749 & 8,321 & 13,409 \\
\hline & 0.082 & 0,523 & 0.895 & 0,077 & 0.029 & 0,000 & 0,077 & 0.620 & 0,002 & 0,188 & 0,081 & 0,009 \\
\hline
\end{tabular}

style

Notes: a. In general, a good fit to the data is indicated by high p-values ( p-value does for sure exceeds the significant level $\mathrm{a}=5 \%$ ) in the analysis of variance, meaning that the variables/criteria contribute equivalently to the structure of each level/factor and explain them. b. $a=$ coefficient of $\alpha$ Cronbach, which is statistically significant when ranges in value from 0,70 to 1 .

* = the Bank type equal with 1 (it means, "Full Service” Branch)

** = the Bank type equal with 2 (it means, “ Medium - Sized Business and Individual” Branch),

$* * *=$ the Bank type equal with 3 (it means, "Individual Customers Service” Branch) 


\begin{tabular}{|c|c|c|c|c|c|c|c|c|}
\hline \multirow{2}{*}{ Table 2.b } & \multicolumn{4}{|c|}{ Age $\mathbf{3}$ * } & \multicolumn{4}{c|}{ Age $=4$ ** } \\
\hline \multirow{2}{*}{ Directive } & Com/ment & Satis/on & Com/on & Ef/ness & Com/ment & Satis/on & Com/on & Ef/ness \\
\hline & 37,835 & 100,033 & 38,219 & 16,738 & 11,877 & 27,383 & 11,917 & 22,327 \\
& 0,000 & 0,000 & 0,000 & 0,033 & 0,220 & 0,001 & 0,218 & 0,001 \\
\hline Empowering & 57,552 & 96,484 & 62,291 & 21,098 & 8,856 & 21,632 & 16,020 & 9,098 \\
& 0,000 & 0,000 & 0,000 & 0,007 & 0,715 & 0,042 & 0,190 & 0,334 \\
\hline Transformational & 35,668 & 56,190 & 23,535 & 15,092 & 7,444 & 28,401 & 10,981 & 11,056 \\
& 0,000 & 0,000 & 0,001 & 0,020 & 0,282 & 0,000 & 0,089 & 0,026 \\
\hline Transactional & 12,846 & 34,072 & 4,041 & 4,820 & 9,605 & 3,407 & 6,558 & 10,576 \\
& 0,012 & 0,000 & 0,400 & 0,306 & 0,142 & 0,756 & 0,364 & 0,032 \\
\hline
\end{tabular}

* the Age 3, means age: $36-45$

**the Age 4, means age: 46-60

\begin{tabular}{|c|c|c|c|c|c|c|c|c|c|c|c|c|}
\hline \multirow[t]{2}{*}{ Table 2.c } & \multicolumn{4}{|c|}{ Education $=2$ \# } & \multicolumn{4}{|c|}{ Education $=3^{\text {thk }}$} & \multicolumn{4}{|c|}{ Education $=4$ *t* } \\
\hline & Com/ment & Satis/on & Com/on & Ef/ness & Com/ment & Satis/on & Com/on & Ef/ness & Com/ment & Satis/on & Com/on & Ef/ness \\
\hline \multirow[t]{2}{*}{ Directive } & 27,072 & 14,489 & 22,903 & 17,659 & 60,263 & 107,343 & 61,007 & 61,761 & 5,333 & 12,000 & 5,333 & 5,400 \\
\hline & 0,440 & 0,070 & 0,029 & 0,126 & 0,000 & 0,000 & 0,000 & 0,000 & 0,149 & 0,062 & 0,149 & 0,494 \\
\hline \multirow[t]{2}{*}{ Empowering } & 17,926 & 16,300 & 21,295 & 16,476 & 48,589 & 91,277 & 55,171 & 42,900 & 8,000 & 12,000 & 5,333 & 5,400 \\
\hline & 0,118 & 0,038 & 0,046 & 0,170 & 0,000 & 0,000 & 0,000 & 0,000 & 0,046 & 0,062 & 0,149 & 0,494 \\
\hline \multirow[t]{2}{*}{ Ttransformatonal } & 22,120 & 9,998 & 18,525 & 17,398 & 53,287 & 76,905 & 52,410 & 38,867 & 2,667 & 3,000 & 2,667 & 1,200 \\
\hline & 0,036 & 0,125 & 0,030 & 0,043 & 0,000 & 0,000 & 0,000 & 0,000 & 0,102 & 0,223 & 0,102 & 0,549 \\
\hline \multirow[t]{2}{*}{ Transactional } & 6,519 & 1,313 & 2,311 & 11,989 & 10,377 & 22,071 & 7,199 & 12,610 & 4,444 & 10,667 & 4,444 & 5,400 \\
\hline & 0,368 & 0,859 & 0,889 & 0,062 & 0,035 & 0,001 & 0,126 & 0,050 & 0,108 & 0,031 & 0,108 & 0,249 \\
\hline
\end{tabular}

* the Education equal with 2 (it means, managers hold Bachelor)

** the Education equal with 3(it means, managers hold University degree)

***the Education equal with 4 (it means, managers hold Master)

Table 3. Dependence- independence

\begin{tabular}{|l|r|r|r|}
\hline & Bank 1 & Bank 2 & Bank 3 \\
\hline Directive-Commitment & dependence & dependence & dependence \\
\hline Empowering- Commitment & dependence & independence & dependence \\
\hline Transformational-Commitment & dependence & dependence & dependence \\
\hline Transactional- Commitment & independence & dependence & dependence \\
\hline Directive-Satisfaction & dependence & dependence & dependence \\
\hline Empowering- Satisfaction & dependence & dependence & dependence \\
\hline Transformational-Satisfaction & dependence & dependence & dependence \\
\hline
\end{tabular}




\begin{tabular}{|l|r|r|r|}
\hline Transactional- Satisfaction & independence & dependence & independence \\
\hline Directive-Communication & dependence & dependence & dependence \\
\hline Empowering- Communication & dependence & dependence & dependence \\
\hline Transformational-Communication & dependence & dependence & dependence \\
\hline Transactional- Communication & independence & independence & independence \\
\hline Directive-Effectiveness & dependence & dependence & dependence \\
\hline Empowering- Effectiveness & dependence & dependence & dependence \\
\hline Transformational-Effectiveness & dependence & dependence & dependence \\
\hline Transactional- Effectiveness & independence & independence & dependence \\
\hline
\end{tabular}

\begin{tabular}{|l|r|r|}
\hline & Age 3 & Age 4 \\
\hline Directive-Commitment & dependence & independence \\
\hline Empowering- Commitment & dependence & independence \\
\hline Transformational-Commitment & dependence & independence \\
\hline Transactional- Commitment & dependence & independence \\
\hline Directive-Satisfaction & dependence & dependence \\
\hline Empowering- Satisfaction & dependence & dependence \\
\hline Transformational-Satisfaction & dependence & dependence \\
\hline Transactional- Satisfaction & dependence & independence \\
\hline Directive-Communication & dependence & independence \\
\hline Empowering- Communication & dependence & independence \\
\hline Transformational-Communication & dependence & independence \\
\hline Transactional- Communication & independence & independence \\
\hline Directive-Effectiveness & dependence & dependence \\
\hline Empowering- Effectiveness & dependence & independence \\
\hline Transformational-Effectiveness & dependence & dependence \\
\hline Transactional- Effectiveness & independence & dependence \\
\hline
\end{tabular}




\begin{tabular}{|c|c|c|c|}
\hline & Education 2 & Education 3 & Education 4 \\
\hline Directive-Commitment & independence & dependence & independence \\
\hline Empowering- Commitment & independence & dependence & dependence \\
\hline Transformational-Commitment & dependence & dependence & independence \\
\hline Transactional- Commitment & independence & dependence & independence \\
\hline Directive-Satisfaction & independence & dependence & independence \\
\hline Empowering- Satisfaction & dependence & dependence & independence \\
\hline Transformational-Satisfaction & independence & dependence & independence \\
\hline Transactional- Satisfaction & independence & dependence & dependence \\
\hline Directive-Communication & dependence & dependence & independence \\
\hline Empowering- Communication & dependence & dependence & independence \\
\hline Transformational-Communication & dependence & dependence & independence \\
\hline Transactional- Communication & independence & independence & independence \\
\hline Directive-Effectiveness & independence & dependence & independence \\
\hline Empowering- Effectiveness & independence & dependence & independence \\
\hline Transformational-Effectiveness & dependence & dependence & independence \\
\hline Transactional- Effectiveness & independence & independence & independence \\
\hline
\end{tabular}

